\title{
Effets des fibres et des matières grasses protégées sur la composition du lait de chèvre
}

\author{
MC Rousselot 1, CB Broqua 1, C de Araujo 2, LP Borgida 2 \\ IInstitut de l'Elevage, Agropole, 86800 Mignaloux-Beauvoir ; 2 COFNA, BP 1807, 37018 Tours Cedex, France
}

Les laits de chèvre de milieu et fin de lactation peuvent présenter un taux de matières grasses faible. La distribution aux animaux d'aliments cellulosiques fibreux à forte ingestibilité et/ou l'apport de matières grasses protégées pourraient constituer deux remèdes possibles.

L'essai a été mené de la 12 ème à la 41 ème semaine de lactation sur 4 lots de 12 chèvres Alpines. Les 4 rations complètes comparées comprenaient environ $50 \%$ de fourrage de base (ensilage de mais au cours des 8 premières semaines puis ensilage de ray-grass italien (RGI)). La ration témoin $T$ était composée de tourteau de soja (14\%), d'orge $(17 \%)$ et de foin de RGI. La ration F contenait $29 \%$ d'un aliment fibreux et $22 \%$ d'un concentré azoté. La ration MG renfermait du foin de RGI (16\%), un concentré azoté ( $27 \%$ ) et des matières grasses protégées (sels de calcium d'huile de palme, $4 \%$ ). Enfin, la ration $F+M G$, outre un concentre azoté $(10 \%)$, regroupait l'aliment fibreux utilisé dans la ration $F(33 \%)$ et les MG $(3 \%)$.

Les 4 rations ont été formulées de manière à être iso-azotées et à couvrir les besoins UFL et $P D I$ des chèvres. Les rations $T$ et $F$ étaient iso-énergétiques $(0,9 \mathrm{UFL} / \mathrm{kg} \mathrm{MS})$ et se caractérisaient par un faible niveau d'apport de lipides alimentaires (2,6 à $3,4 \%$ de la MS). La concentration énergétique, estimée, des rations $M G$ et $F+M G$ était de $1 \mathrm{UFL} / \mathrm{kg}$ MS et leur taux de lipides s'élevait à $7,5 \%$ de la MS. Les 2 rations contenant l'aliment fibreux présentaient des teneurs en cellulose brute de
$22 \%$ contre $18 \%$ pour les 2 autres rations. Enfin, le pourcentage d'amidon + sucre était de $23 \%$ pour la ration $T$ contre $17 \%$ pour les autres rations. Les données individuelles et bihebdomadaires de production laitière ont été soumises à des analyses de variance.

L'apport de fibres peu encombrantes a stimulé l'ingestion de MS totale (de $+0,12$ à $+0,27 \mathrm{~kg} / \mathrm{j}$ ). En revanche, l'apport de MGP n'a apparemment eu aucun effet sur le niveau d'ingestion. La production de lait brut a été plus élevée pour les 3 lots recevant les rations expérimentales (de $+0,28$ à $+0,36 \mathrm{~kg} / \mathrm{j}$ ). L'incorporation de fibres ou de lipides protégés dans la ration a amélioré significativement le TB de, respectivement, 4 et $5,9 \mathrm{~g} / \mathrm{kg}$ par rapport à la ration $T$. Les effets de ces 2 aliments se sont additionnés lorsqu'ils ont été distribués ensemble $(+8,6 \mathrm{~g} / \mathrm{kg})$ car ils ont agit simultanément sur 2 leviers indépendants : les fibres ont favorisé la formation dans le rumen des AGV utilisés par la mamelle pour la synthèse des matières grasses; les lipides protégés ont élevé la proportion d'acides gras alimentaires prélevés par la mamelle. Seules les fibres ont présenté un effet significatif sur le TP : $+1 \mathrm{~g} / \mathrm{kg}$ par rapport à la ration $\mathrm{T}$.

L'utilisation pour le rationnement des chèvres d'aliments fibreux et de lipides protégés est un moyen fiable de remédier aux taux butyreux faibles des laits de milieu et fin de lactation, dans la mesure où leur emploi permet de rééquilibrer la ration.

\begin{tabular}{lcccc}
\hline Ration & $\mathrm{T}$ & $\mathrm{F}$ & $\overline{\mathrm{MG}}$ & $\overline{\mathrm{F}}+\mathrm{MG}$ \\
\hline MS ingérée $(\mathrm{kg} / \mathrm{j})$ & 2,42 & 2,69 & 2,42 & 2,54 \\
Lait brut $(\mathrm{kg} / \mathrm{j})$ & 2,64 ns & $2,92^{\text {ns }}$ & $2,98^{\mathrm{ns}}$ & $3,00^{\mathrm{ns}}$ \\
TB $(\mathrm{g} / \mathrm{kg})$ & $28,7^{\mathrm{a}}$ & $32,7^{\mathrm{b}}$ & $34,6^{\mathrm{b}}$ & $37,3^{\mathrm{c}}$ \\
TP $(\mathrm{g} / \mathrm{kg})$ & $28,0^{\mathrm{d}}$ & $29,0 \mathrm{e}$ & $28,7^{\mathrm{de}}$ & $29,0 \mathrm{e}$ \\
\hline
\end{tabular}

ns : Effet non significatif

$a, b, c$ : différences significatives au seuil $P<0,001$

$d_{1} e$ : différences significatives au seuil $P<0,05$ 